\title{
Acute onset of cerebellar ataxia in a spinocerebellar ataxia type 10 patient after use of steroids
}

\author{
Início agudo de ataxia cerebelar em paciente com ataxia espinocerebelar tipo 10 após o \\ uso de corticosteroides
}

\author{
Adriana Moro', Renato P. Munhoz, ${ }^{1,2}$, Salmo Raskin³, Torben C. Bezerra' ${ }^{1}$ Mariana Moscovich4, \\ Tetsuo Ashizawa4, Hélio A.G. Teive'
}

${ }^{1}$ Movement Disorders Unit, Neurology Service, Internal Medicine Department, Hospital de Clínicas, Federal University of Paraná, Curitiba PR, Brazil;

${ }^{2}$ Neurology Department, Pontificial Catholic University of Paraná, Curitiba PR, Brazil;

${ }^{3}$ Genetika Laboratory, Curitiba PR, Brazil;

${ }^{4}$ Department of Neurology, University of Florida, Gainesville FL, USA.

Correspondence: Hélio A.G. Teive; Rua General Carneiro 1.103 / 102; 80060-150 Curitiba PR - Brasil; E-mail: hagteive@mps.com.br

Conflict of interest: Doctor Ashizawa is funded by NINDS grant RC1NS068897, National Ataxia Foundation, Marigold Foundation. The remaining authors have nothing to disclose.

Received 30 May 2012; Received in final form 06 June 2012; Accepted 14 June 2012

Spinocerebellar ataxia type 10 (SCA10) is an autosomal dominant disorder caused by an expansion of a pentanucleotide (ATTCT) repeat in intron 9 of the ATXN10 gene on chromosome $22 q 13.3^{1,2}$. SCA10 gene encodes a $475 \mathrm{KD}$ protein of largely undetermined function. The pathogenic number of ATTCT repeat units ranges from 800 to 4,500 repeats. SCA10 represents a rare form of SCA, described only in Latin America $^{1,2}$. While clinical manifestations of families described in Brazil are those of a predominantly "pure" cerebellar syndrome, it is often accompanied by epilepsy and occasionally peripheral neuropathy in the Mexican ones ${ }^{1,2}$.

Here, we presented the case of a patient with genetically confirmed SCA10, who developed sudden onset of cerebellar ataxia after a course of corticosteroid therapy.

A 34-year-old previously asymptomatic Brazilian woman suddenly developed gait ataxia and dysarthria two weeks after a pulse therapy with methylprednisolone for the treatment of idiopathic thrombocytopenic purpura. The patient was admitted with a clinical picture of body petechiae, gingival bleeding, and hematochezia, which started four days earlier. She had a platelet count of 1,000, which improved with the use of corticosteroids. Neurological assessment revealed gait ataxia, dysarthria, and ocular dysmetria. The Scale for the Assessment and Rating of Ataxia (SARA) was 7.5. Brain magnetic resonance imaging (MRI) showed moderate cerebellar atrophy. Family history was positive for SCA10, including previously reported relatives (aunt and two cousins), whose symptoms were initially manifested during pregnancy ${ }^{3}$. Interestingly, this same family has also reported the occurrence of cerebellar symptoms triggered by ingestion of small amounts of alcohol, which was previously also published by the authors ${ }^{4}$.

SCA10 is the second most common autosomal dominant cerebellar ataxia in Brazil (after SCA type 3) and in Mexico (after SCA 2). To our knowledge, there is no report of acute cerebellar ataxia development after steroid therapy in patients with SCAs. Based on the case reported here and on family history of onset of symptoms during pregnancy and on postpartum peri$\mathrm{od}^{3}$, the authors hypothesized that hormonal factors may have a role in the emergence of SCA10 clinical symptoms and signs in previously asymptomatic patients in this family. The mechanisms by which hormones act on cerebellar function and its afferent and efferent connections remain unknown.

Previously established genetic variables could be responsible for a lower threshold for manifestation of SCA10 in the course of steroid therapy, and additional studies are necessary to confirm this finding. On the other hand, it is widely known that stress seems to cause acute neuronal death or dysfunction ${ }^{5}$. Therefore, another possibility is that factors related to stress, involved in acute medical situations, such as pregnancy and postpartum period, could have a pivotal role in the development of acute symptoms of cerebellar ataxia in patients with asymptomatic cerebellar atrophy due to SCA10.

\section{References}

1. Teive HA, Munhoz RP, Arruda WO, Raskin S, Werneck LC, Ashizawa T. Spinocerebellar ataxia type 10: a review. Parkinsonism Relat Disord 2011;17:655-661. tients with spinocerebellar ataxia 10. Neurology 2004;63:1509-1512.

3. Teive HAG, Arruda WO, Raskin S, et al. Symptom onset of spinocerebellar ataxia type 10 in pregnancy and puerperium.J Clin Neurosci 2011;18:437-438.
4. Teive HAG, Munhoz RP, Ashizawa T. Spinocerebellar ataxia type 10: disproportionate cerebellar symptoms among at-risk subjects induced by small amounts of alcohol. Arq Neuropsiquiatr 2011;69:841-850.

5. Swaab DF, Bao A, Lucassen PJ. The stress system in the human brain in depression and neurodegeneration. Ageing Res Rev 2005;4:141-194 